\title{
IDENTIFICAÇÃO DE CULTIVARES DE MILHO, FEIJÃO, ALGODÃO E SOJA POR MEIO DE ENZIMAS E PROTEÍNAS RESISTENTES AO CALOR'.
}

\author{
MARINEY DE MENEZES ${ }^{2}$, ÉDILA VILELA DE RESENDE VON PINHO ${ }^{3}$, ANTÔNIO \\ MARCOS DE ANDRADE REZENDE PEREIRA4 ${ }^{4}$, JOÃO ALMIR DE OLIVEIRA ${ }^{3}$.
}

\begin{abstract}
RESUMO - Nesta pesquisa foram avaliados o polimorfismo e a estabilidade de isoenzimas e de proteínas resistentes ao calor em sementes de cultivares de milho, feijão, algodão e soja, com diferentes níveis de qualidade fisiológica. As isoenzimas, álcool desidrogenase, catalase, esterase e superóxido dismutase analisadas conjuntamente, foram eficientes na separação de oito cultivares de milho. Para as cultivares de feijão, pela enzima peroxidase foi possível diferenciar a cultivar Carioca, no entanto, este padrão mostrou-se variável em sementes com baixa germinação. Não foi possível diferenciar as cultivares de algodão pelas enzimas esterase, superóxido dismutase, diaforase e malato desidrogenase. A cultivar Conquista, de soja, foi diferenciada pelos sistemas enzimáticos esterase e superóxido dismutase e a 'BRS-154' pela esterase. Proteínas resistentes ao calor são polimórficas e estáveis para a identificação de cultivares de milho.
\end{abstract}

Termos para indexação: sementes, pureza genética, marcador molecular, qualidade fisiológica.

\section{CULTIVARS IDENTIFICATION OF CORN, BEAN, COTTON AND SOYBEAN USING ENZYMES AND HEAT-RESISTANT PROTEINS.}

\begin{abstract}
In this study the polymorphism and stability of isoenzymes and heat-resistant proteins in corn, bean, cotton, and soybean seeds with different levels of physiological quality were evaluated. The alcohol dehydrogenase, catalase, esterase and superoxide dismutase enzymes and simultaneous analysis were effective in identifying eight corn cultivars. It was observed for the bean cultivars that the peroxidase enzyme allowed differentiation of the Carioca bean cultivar from the others but, the peroxidase enzyme pattern varied in seeds with low-germination percentage. The varieties of cotton could not be differentiated by esterase enzyme, superoxide dismutase, diaphorase and malate dehydrogenase. The Conquista soybean cultivar was separated by superoxide dismutase and esterase enzyme systems and BRS-154 was separated by esterase. Heat-resistant protein patterns showed polymorphism and were stable for corn cultivar identification.
\end{abstract}

Index terms: seeds, genetic purity, molecular marker, physiological quality.

\footnotetext{
${ }^{1}$ Submetido em 15/08/2007. Aceito para publicação em 19/03/2008. Parte da dissertação de mestrado do primeiro autor apresentada a UFLA, em 2005; trabalho financiado pela CAPES. ${ }^{2}$ Eng. Agr ${ }^{\circ}$.; Pós Doctoranda Júnior do Departamento de Genética e Melhoramento de Plantas, UFLA,
}

email: marineym@gmail.com. ${ }^{3}$ Eng. Agr ${ }^{\circ}$; Dr $^{\circ}$ (a); Professor (a) Titular, Departamento de Fitotecnia, Universidade Federal de Lavras -UFLA. Caixa Postal 3037, Lavras, MG. CEP: 37200-000. Lavras, MG. ${ }^{4}$ Eng. $\mathrm{Agr}^{\circ}$.; doutorando do Departamento de Fitotecnia, UFLA. 


\section{INTRODUÇÃO}

A identificação de cultivares é de fundamental importância no controle de qualidade de sementes e na crescente necessidade de proteção de cultivares. Com a aprovação da Lei de Proteção de Cultivares, n 9.456 , sancionada no Brasil em 25 de abril de 1997, tornou-se possível proteger as variedades vegetais desenvolvidas nos programas de melhoramento genético. É importante observar que, para a proteção de uma nova cultivar, a mesma deverá ser registrada e submetida ao teste de DHE (distinguibilidade, homogeneidade e estabilidade).

A identificação de cultivares tem sido realizada principalmente por meio de marcadores morfológicos de sementes, plântulas e plantas nas fases de florescimento e maturação (Silva, 1997). Esses marcadores têm sido utilizados para diferenciação de várias espécies (Vieira, 2000; Salgado, 2001; Vieira, 2004; Bonow 2004). Porém, podem apresentar variáveis dependendo do tecido analisado, da ocorrência de microrganismo em associação com esses tecidos, da adubação e das condições ambientais (Silva, 1997; Imolesi, 1999). Mediante tal situação, torna-se necessário estudar o polimorfismo, assim como a estabilidade de enzimas para identificação de cultivares em várias espécies.

Um outro grupo de proteínas que tem apresentado potencial para a identificação de cultivares é o de proteínas resistentes ao calor. Essas proteínas são hidrofílicas, abundantes, extraídas em condições de altas temperaturas, e são armazenadas nos últimos estádios de desenvolvimento das sementes. Porém, essas proteínas têm sido pouco estudadas com relação à estabilidade e polimorfismo. Sendo assim, foram avaliados o polimorfismo e a estabilidade das enzimas e das proteínas resistentes ao calor para a identificação de cultivares de milho, feijão, algodão e soja em sementes com diferentes níveis de qualidade fisiológica.

\section{MATERIAL E MÉTODOS}

O trabalho foi realizado nos laboratórios de Análise de Sementes e de Eletroforese do Departamento de Agricultura da Universidade Federal de Lavras (UFLA), no município de Lavras, região de Minas Gerais. Foram utilizadas sementes de linhagens e híbridos de milho da empresa da Geneseeds Recursos Genéticos em Milho Ltda, identificadas como: 1, 1/11, 11, 3, 8/3, 8, 4, 11/4, 5, 12/5 e 12; as cultivares de feijão: Carioca, Carioca MG, Aporé, Pérola, IAPAR 57 e IAPAR 81; as cultivares de soja: Conquista, Monarca, Liderança,
Confiança, Splendor, UFV-16, Garantia, FT-2000, BRIAC21, Vencedora, BRS 133, BRS 154, BRS 216, CD 201, CD 208, IAC 15-2, M-Soy 6101, M-Soy 8001 e M-Soy 8411 e as cultivares de algodão EPAMIG-Precoce, MG-110, MG0304, MG-0316 e MG 0305.

O teor de água das sementes foi determinado pelo método da estufa a $105^{\circ} \mathrm{C}$ por 24 horas (Brasil, 1992). Para avaliar a estabilidade das proteínas resistentes ao calor parte das sementes foi submetida à deterioração controlada para a obtenção de sementes com diferentes níveis de qualidade. As sementes foram colocadas em BOD a $42^{\circ} \mathrm{C}$ por 48 horas para o milho, 96 horas para a soja, 108 horas para o algodão e 120 horas para o feijão. Para a avaliação da qualidade fisiológica foi realizado o teste germinação e as avaliações foram efetuadas segundo as recomendações das Regras para Análise de Sementes (Brasil, 1992).

Para a extração das isoenzimas de milho seguiuse a metodologia utilizada por Imolesi (1999). Após a eletroforese, os géis foram revelados e corados para os sistemas isoenzimáticos: esterase, álcool desidrogenase, malato desidrogenase e catalase, segundo Alfenas et al (1991).

Os processos de extração e revelação das isoenzimas das cultivares de feijão foram realizados de acordo com Vieira (2000). Os géis foram revelados para os sistemas enzimáticos esterase, peroxidase e glutamato-oxalacetato transaminase, seguindo as prescrições de Alfenas et al (1991).

Para a extração das isoenzimas de algodão seguiu-se o protocolo de Vieira (1996). Terminada a corrida, os géis foram revelados para os sistemas enzimáticos esterase, diaforase, superóxido-dismutase e malato desidrogenase, conforme Alfenas et al. (1991).

Já para a soja foram utilizados $100 \mathrm{mg}$ de epicótilos de plântula de cada cultivar com cinco dias de germinação, segundo o protocolo de Aguerro (2002). Após a eletroforese os géis foram revelados para os sistemas enzimáticos diaforase, esterase e superóxido dismutase de acordo com Alfenas et al (1991).

Para a separação das isoenzimas, foi usado um gel de poliacrilamida que é constituído de duas partes: 7,5\% (gel separador) e 4,5\% (gel concentrador). O sistema tampão gel/ eletrodo foi o Tris-glicina $\mathrm{pH} 8,9$. As corridas eletroforéticas foram efetuadas a $150 \mathrm{~V}$ por 4 horas.

Para as extrações das proteínas resistentes ao calor, adotou-se o protocolo utilizado por Vieira (2004).

$\mathrm{Na}$ avaliação dos padrões protéicos tanto de enzimas como de proteínas resistentes ao calor foi observada a presença e ausência de bandas em cada genótipo, designadas 
por 0 e 1, respectivamente. Foi construída uma matriz de 0 e 1 e a estimativa da similaridade genética (Sgij) entre cada par de genótipos foi calculada pelo coeficiente de Jaccard, pela seguinte expressão:

Coeficiente de Jaccard: $s g i j=\frac{a}{a+b+c}$, sendo:

$\mathrm{a}=$ presença da banda em ambos os genótipos $\mathrm{i}$ e $\mathrm{j}$,

$\mathrm{b}=$ presença da banda no indivíduo $\mathrm{i}$ e ausência no indivíduo $\mathrm{j}$,

$\mathrm{c}=$ ausência da banda no indivíduo i e presença no indivíduo $\mathrm{j}$.

Com base no coeficiente de similaridade de Jaccard, os genótipos foram agrupados pelo método UPGMA (Unweighted Pair-Group Method), utilizando-se o programa NTSYS versão 2.11 (Rohlf, 1992).

Para a obtenção da linha de corte no dendrograma, o erro (sgs) associado a cada similaridade genética foi calculado pela fórmula:

$\mathrm{Sgs}=\left[\mathrm{gs}_{\mathrm{ij}} *\left(1-\mathrm{gs}_{\mathrm{ij}}\right) /(\mathrm{n}-1)\right]^{*} 0,5$.

em que:

sgs $=$ erro $\mathrm{gs}_{\mathrm{ij}}=$ similaridade genética

$\mathrm{n}=$ número total de bandas polimórficas obtidas.

Após, o valor da linha de corte (gsn) foi calculado aplicando-se o erro médio na seguinte fórmula (Hagiwara et al., 2001):

$\mathrm{gsn}=1-\left(\mathrm{t}_{\mathrm{x} \%} *\right.$ erro médio $)$.

em que:

gsn $=$ valor da linha de corte

$\mathrm{t}_{\mathrm{x} \%}=$ valor de $\mathrm{t}$ com $\mathrm{n}-2$ graus de liberdade

\section{RESULTADOS E DISCUSSÃO}

\section{Milho}

Os valores iniciais de teores de água das sementes de milho, antes de serem submetidas ao processo de deterioração controlada variaram de 10,93 a 12,44\%. Após a deterioração das mesmas esse valor foi elevado para $20 \%$. Menores valores de germinação (Tabela 1) foram observadas em sementes de milho das cultivares $1,1 / 11,11,3,8,4$ e $11 / 4$ submetidas à deterioração controlada por 48 horas.

TABELA 1. Valores médios, em porcentagem, de plântulas normais obtidas no teste de germinação de sementes de milho submetidas e não à deterioração controlada.

\begin{tabular}{cccc}
\hline & & \multicolumn{2}{c}{$20 \%$ de Umidade final das sementes medido após a D.C. } \\
\cline { 3 - 4 } Cultivares & Umidade inicial & \multicolumn{2}{c}{ Período de Deterioração Controlada } \\
\cline { 3 - 4 } & $(\%)$ & 0 horas & Germinação (\%) \\
\hline 1 & 10,93 & $91,00 \mathrm{a}$ & $52,50 \mathrm{~b}$ \\
$1 / 11$ & 16,39 & $89,00 \mathrm{a}$ & $81,50 \mathrm{~b}$ \\
11 & 11,4 & $83,00 \mathrm{a}$ & $56,50 \mathrm{~b}$ \\
3 & 12,44 & $90,50 \mathrm{a}$ & $58,50 \mathrm{~b}$ \\
$8 / 3$ & 11,09 & $99,50 \mathrm{a}$ & $91,75 \mathrm{a}$ \\
8 & 12,37 & $95,50 \mathrm{a}$ & $79,50 \mathrm{~b}$ \\
4 & 11,87 & $94,50 \mathrm{a}$ & $78,00 \mathrm{~b}$ \\
$11 / 4$ & 11,54 & $98,00 \mathrm{a}$ & $76,50 \mathrm{~b}$ \\
5 & 11,96 & $88,00 \mathrm{a}$ & $85,00 \mathrm{a}$ \\
$12 / 5$ & 12,3 & $94,00 \mathrm{a}$ & $95,50 \mathrm{a}$ \\
12 & 11,68 & $93,25 \mathrm{a}$ & $94,00 \mathrm{a}$ \\
\hline
\end{tabular}

Médias seguidas pela mesma letra, na coluna, não diferem entre si pelo teste de Tukey, a $5 \%$ de probabilidade.

Para os perfis isoenzimáticos do álcool desidrogenase (Figura 1A), foram obtidos dois padrões eletroforéticos diferentes, separando os genótipos em dois grupos (1) 1,
$1 / 11,11,8 / 3,4,11 / 4$ e $12 / 5$ e (2) $3,8,5$ e 12 . Não foram observadas modificações nos padrões eletroforéticos em sementes submetidos ou não à deterioração controlada. 
Os padrões dessa enzima, em sementes, podem ser alterados na presença de patógenos (Silva, 1997) e com o tempo de envelhecimento (Brandão Junior, 1996). Seis padrões eletroforéticos diferentes foram obtidos para a catalase (Figura 1B), sendo as cultivares separadas em seis grupos: (1) 11,3 e $8 / 3$; (2) $5,12 / 5$ e 12 ; (3) 1 e 4 ; (4) 8; (5) $1 / 11$ e (6) $11 / 4$. O padrão de bandas do híbrido $8 / 3$ foi diferente apenas do parental masculino, impossibilitando a separação entre o híbrido e o parental feminino. Pela enzima esterase (Figura 2), as cultivares foram separadas em oito grupos: (1) 1 e 8 ; (2) 11 e $11 / 4$; (3) 3 e $12 / 5$; (4) $1 / 11$; (5) $8 / 3$; (6) 4 ; (7) 5 e (8) 12 , tendo as cinco últimas cultivares apresentado padrões eletroforéticos únicos. O padrão eletroforético da superóxido dismutase (Figura 3), possibilitou a separação das linhagens 1 e 12 . Não foram detectadas diferenças da atividade dessa enzima entre sementes do mesmo genótipo quando submetidos à deterioração controlada. De acordo com o dendrograma (Figura 4), as linhagens e híbridos foram agrupadas em sete grupos: (1) linhagem 1 e 4; (2) híbrido 12/5; (3) linhagem 5 e 12; (4) híbridos 1/11 e 11/4; (5) linhagem 11 e híbrido 8/3; (6) linhagem 3 e (7) linhagem 8. O maior valor de similaridade genética foi de 0,86 entre a linhagem 11 e o híbrido 8/3, e o valor da linha de corte com $\mathrm{t}$ $\left(\mathrm{t}_{0,1 \%}\right)$, foi de 0.87 . Os agrupamentos que estão à esquerda da linha de corte, ou seja, com similaridade abaixo de 0.87 , são considerados com baixa similaridade genética entre si.

FIGURA 1. Padrões eletroforéticos das isoenzimas álcool desidrogenase (A) e catalase (B) de sementes de linhagens e híbridos de milho, submetidos (D) ou não à deterioração controlada.

A

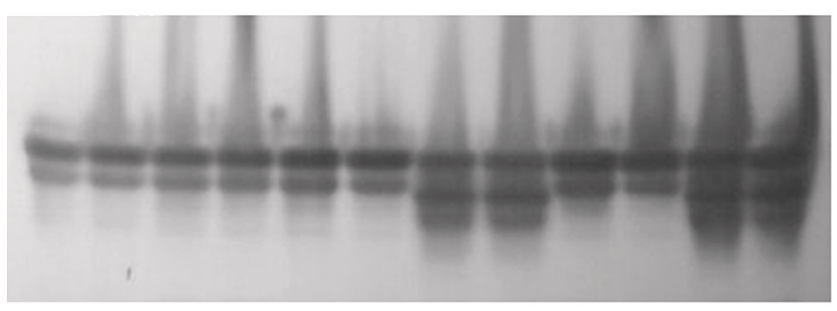

$\begin{array}{llllllllllll}1 \mathrm{D} & 1 & \frac{1 D}{1} & \frac{1}{1} & 11 \mathrm{D} & 11 & 3 \mathrm{D} & 3 & \frac{8 D}{3} & \frac{8}{3} & 8 \mathrm{D} & 8\end{array}$

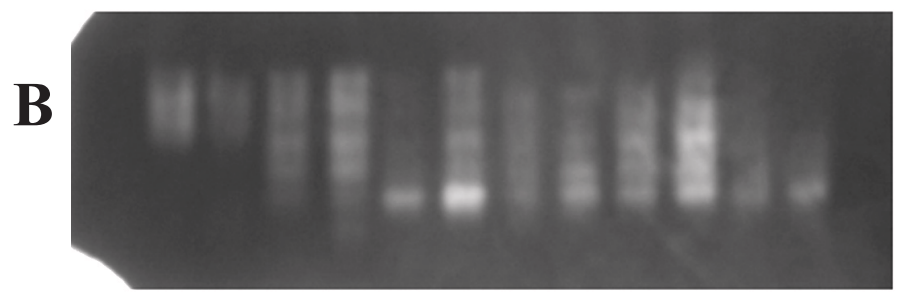

1D $1 \frac{1 D}{1} \quad \frac{1}{1} \quad 11 \mathrm{D} \quad 11 \quad 3 \mathrm{D} \quad 3 \quad \frac{8 D}{3} \quad \frac{8}{3} \quad 8 \mathrm{D} \quad 8$
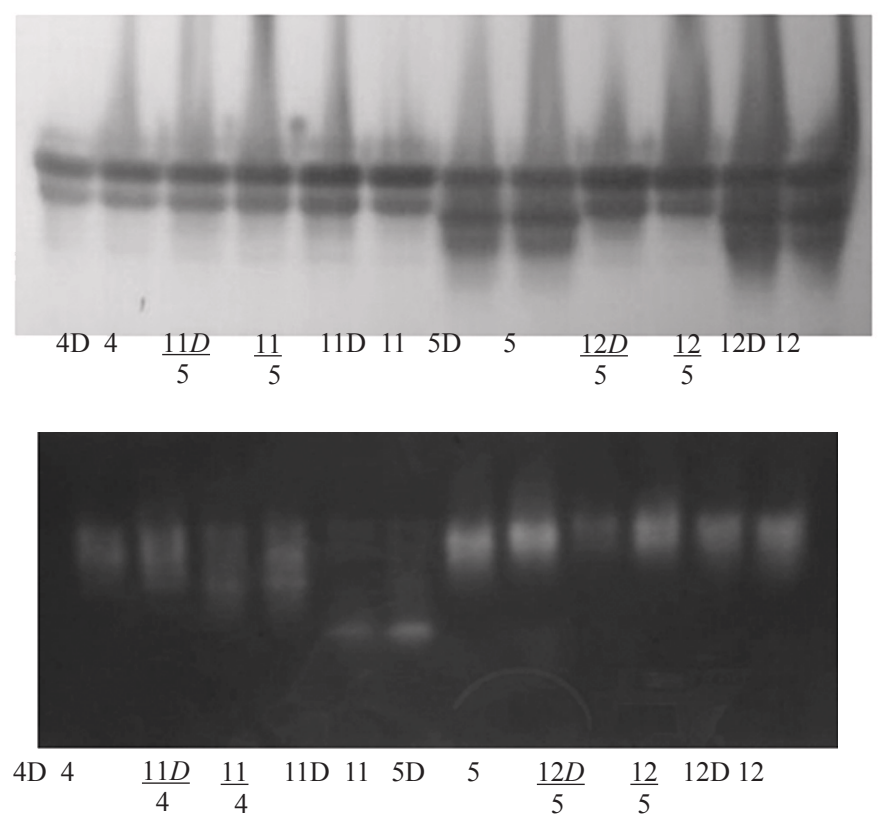

FIGURA 2. Padrões eletroforéticos da isoenzima esterase de sementes de linhagens e híbridos de milho, submetidas (D) ou não à deterioração controlada.

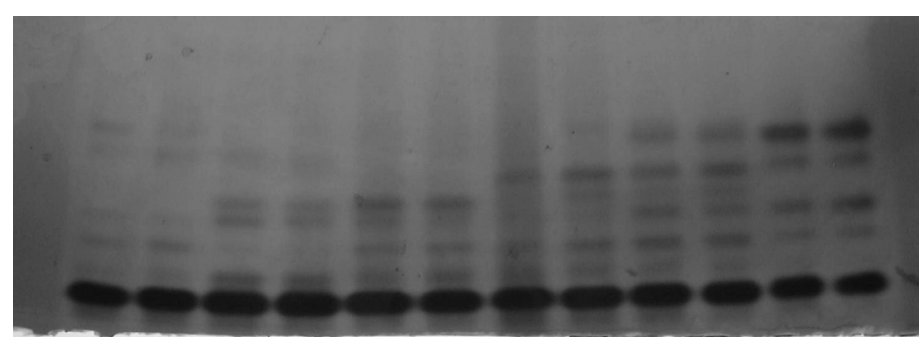

$\begin{array}{lllllllllllll}1 \mathrm{D} & 1 & \frac{1 D}{11} & \frac{1}{11} & 11 \mathrm{D} & 11 & 3 \mathrm{D} & 3 & \frac{8 D}{3} & \frac{8}{3} & 8 \mathrm{D} & 8\end{array}$

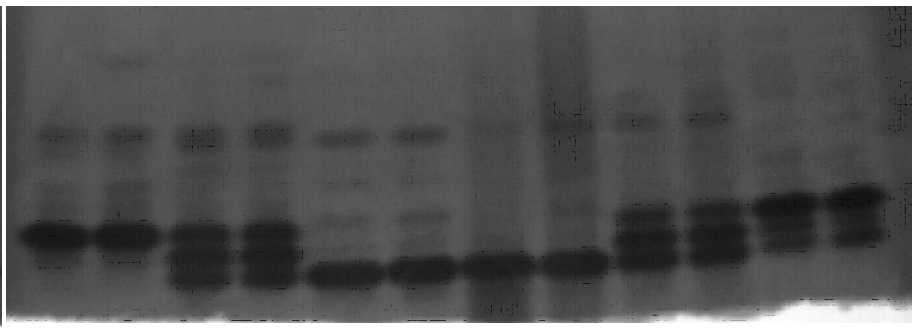

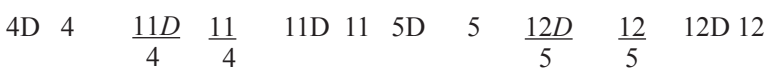


FIGURA 3. Zimograma da isoenzima superóxido dismutase de sementes de linhagens e híbridos de milho, submetidas (D) ou não à deterioração controlada.

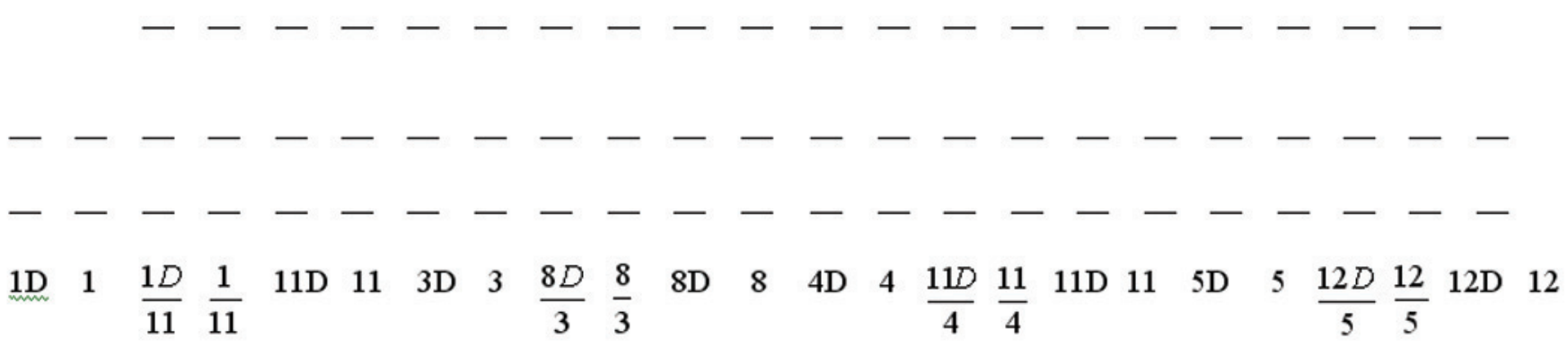

FIGURA 4. Dendrograma de linhagens e híbridos de milho, utilizando marcadores isoenzimáticos em sementes deterioradas e não deterioradas.

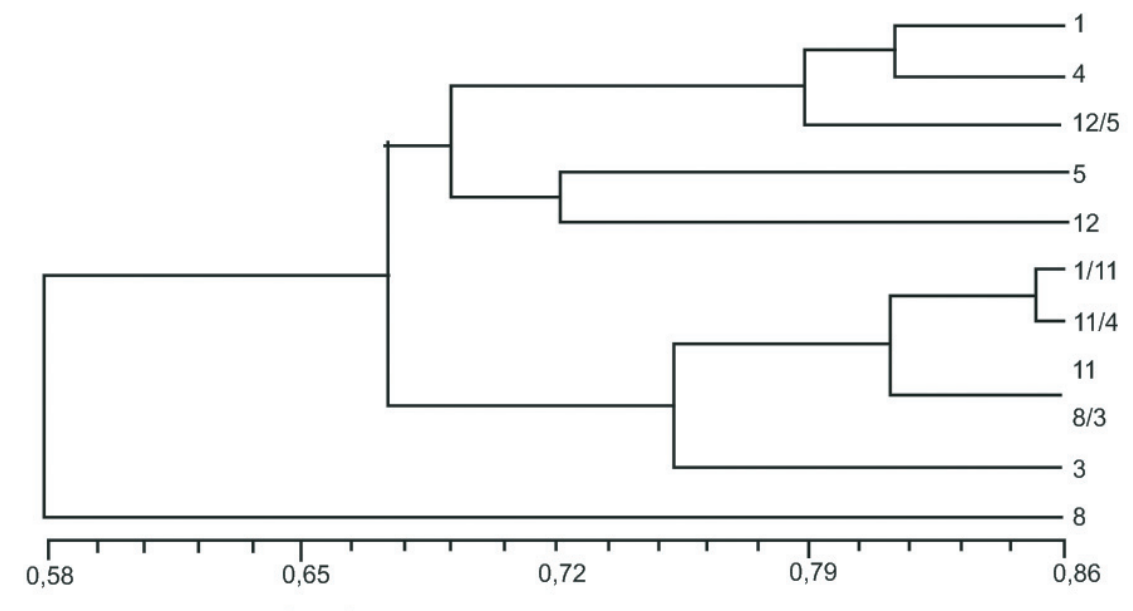

Coeficiente de similaridade

Com relação às proteínas resistentes ao calor (Figura 5), foram analisadas em torno de 15 bandas protéicas, sendo que os padrões eletroforéticos foram diferentes em todas as linhagens e híbridos de milho analisados. Foi observado a banda 1 no híbrido $8 / 3$ e a banda 2 no híbrido $12 / 5$ que representa segregação mendeliana, em que o híbrido possuiu duas bandas, provenientes de cada um dos parentais. Salgado (2001) observou codominância ao avaliar o perfil eletroforético da esterase em sementes de linhagens e híbridos de milho. De acordo com esses resultados, foi observado alto nível de polimorfismo para as proteínas resistentes ao calor nas diferentes linhagens e híbridos utilizados. Resultados semelhantes foram encontrados por Roveri José (2004), ao avaliar o polimorfismo e a estabilidade dessas proteínas em sementes de milho produzidas em diferentes safras e submetidas à secagem natural e artificial.

\section{Feijão}

Os valores iniciais de teores de água das sementes de feijão, antes do processo de deterioração controlada variaram de 11,90 a 12,76\%. Após a deterioração das mesmas esse valor foi elevado para $20 \%$. Os valores de germinação (Tabela 2) das sementes submetidos a 120 horas de deterioração apresentaram-se significativamente $(P<5 \%)$ inferiores quando comparados aos das sementes não-deterioradas. 
FIGURA 5. Padrões eletroforéticos das proteínas resistentes ao calor de sementes de linhagens e híbridos de milho, submetidas (D) ou não à deterioração controlada, obtidos na presença de um padrão protéico (P).

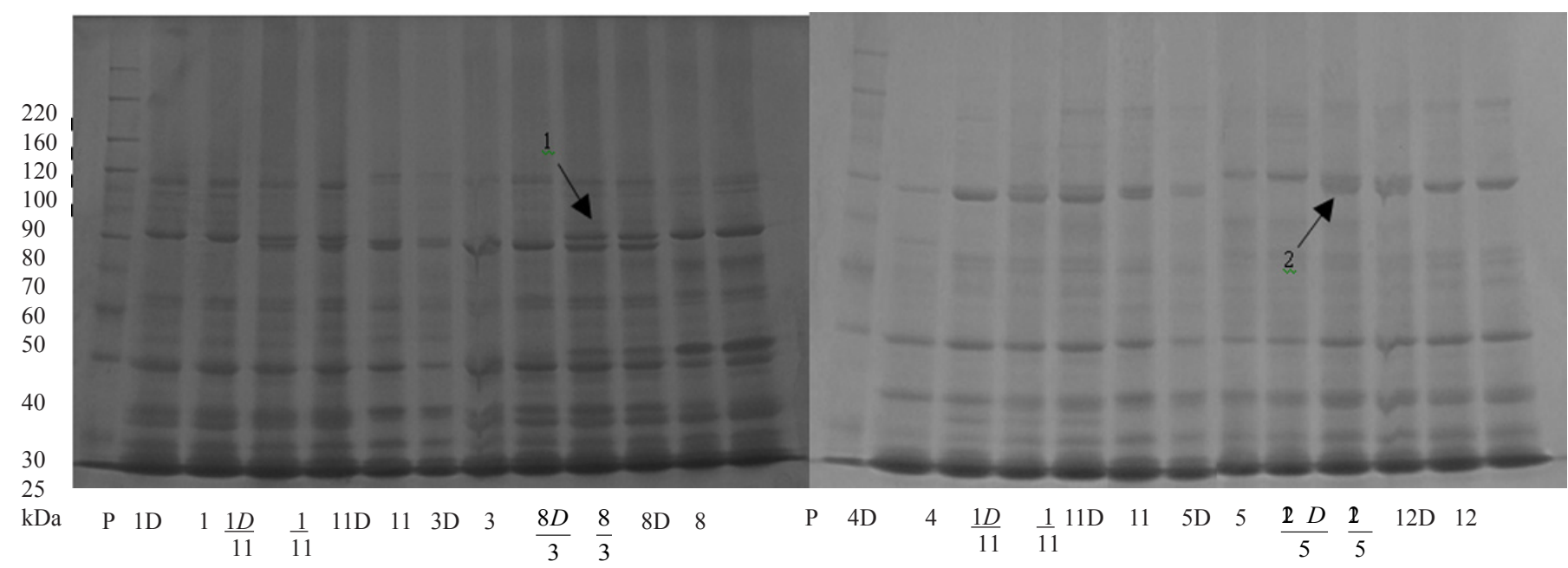

TABELA 2. Valores médios, em porcentagem, de plântulas normais obtidas no teste de germinação de sementes de milho submetidas e não à deterioração controlada.

\begin{tabular}{ccc}
\hline & \multicolumn{2}{c}{$20 \%$ de Umidade final das sementes medido após a D.C. } \\
\cline { 2 - 3 } Cultivares & \multicolumn{3}{c}{ Período de deterioração controlada } \\
\cline { 2 - 3 } & 0 hora & Germinação(\%) \\
\hline Aporé & $98 \mathrm{a}$ & 720 horas \\
Carioca & $97 \mathrm{a}$ & $60 \mathrm{~b}$ \\
Carioca MG & $97 \mathrm{a}$ & $80 \mathrm{~b}$ \\
IAPAR 57 & $99 \mathrm{a}$ & $90 \mathrm{~b}$ \\
IAPAR 81 & $98 \mathrm{a}$ & $55 \mathrm{~b}$ \\
Pérola & $99 \mathrm{a}$ & $58 \mathrm{~b}$ \\
\hline
\end{tabular}

Médias seguidas pela mesma letra, na coluna, não diferem entre si pelo teste de Tukey, a 5\% de probabilidade.

Em relação aos marcadores enzimáticos, observa-se que para a enzima peroxidase houve o aparecimento das bandas 3 e 4 na cultivar Carioca, o que a diferenciou das demais cultivares (Figura 6). Já Vieira (2000) observou padrões de bandas monomórficas dessa enzima para as mesmas cultivares. Dessa forma, constata-se a falta de estabilidade do padrão dessa enzima em diferentes lotes da mesma cultivar. Na presente pesquisa, foi observada ainda diminuição da intensidade das bandas 3 e 4 em sementes deterioradas da cultivar Carioca. Pelo dendrograma obtido a partir dos coeficientes de Jaccard (Figura 7) as seis cultivares de feijão do Grupo Carioca foram separadas em 3 grupos: (1)
Aporé, Carioca MG e IAPAR 57; (2) IAPAR 81 e Pérola e (3) Carioca. A alta similaridade existente entre as cultivares Aporé, Carioca MG e IAPAR 57, provavelmente está relacionada com a existência de um progenitor comum entre as cultivares Aporé e IAPAR 57, sendo este a cultivar Porrilo. Entre as cultivares Carioca MG e Aporé pode ser explicada pela presença de alelos comuns da cultivar Carioca. A grande similaridade verificada entre as cultivares IAPAR 81 e Pérola está relacionada com a existência da cultivar Carioca como progenitor comum. A distinção da cultivar Carioca em relação às demais cultivares provavelmente deve-se à existência de genes provenientes de outra espécie. A similaridade genética 
entre as cultivares pode ser confirmada pela linha de corte referida linha são considerados semelhantes. 0,83 com $\mathrm{t}_{0.1 \%}$, segundo a qual os agrupamentos à direita da

FIGURA 6. Padrão eletroforético da isoenzima peroxidase das cultivares de feijão Aporé (1), Carioca (2), Carioca MG (3), IAPAR 57 (4), IAPAR 81 (5) e Pérola (6), submetidas (D) ou não à deterioração controlada.

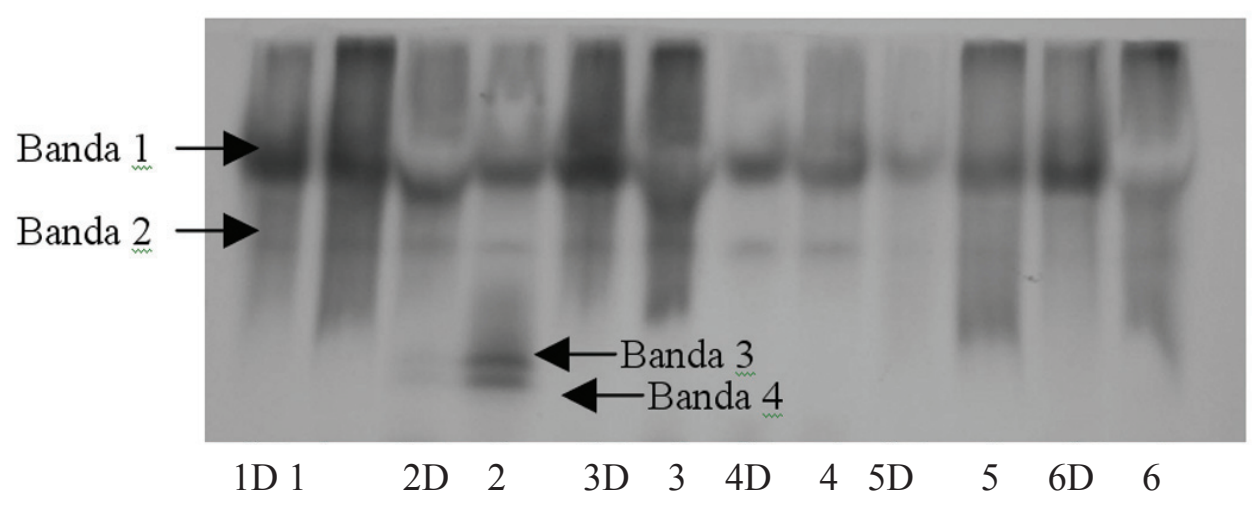

FIGURA 7. Dendrograma de linhagens e híbridos de milho, utilizando marcadores isoenzimáticos em sementes deterioradas e não deterioradas.

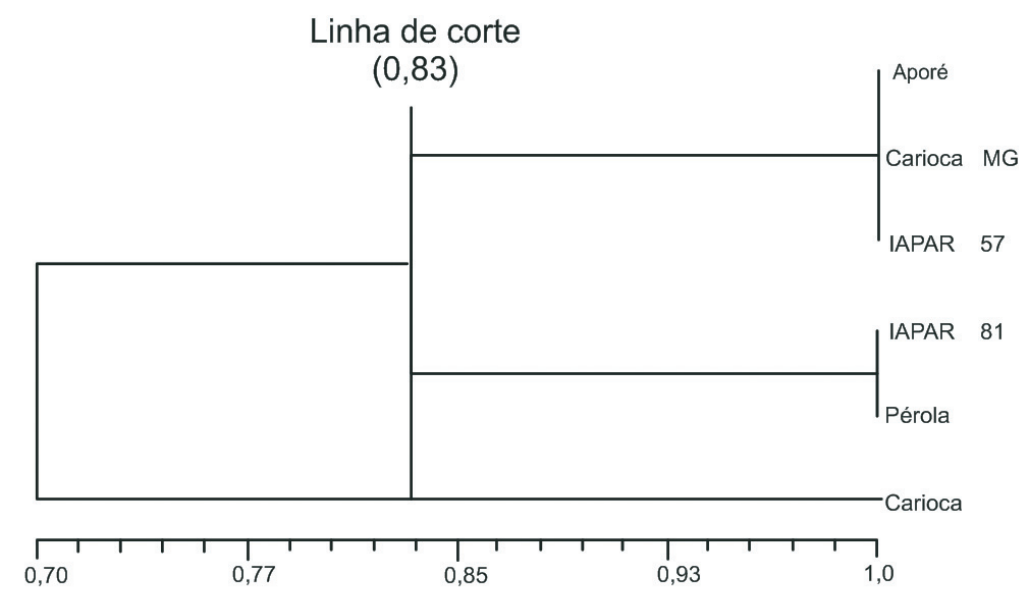

Coeficiente de similaridade

Para as proteínas resistentes ao calor, não foram encontrados padrões polimórficos entre as cultivares de feijão utilizada. Todas as cultivares possuem parentais em comum, sendo que esse tipo de marcador não é eficiente como descritor em cultivares com base genética estreita.

\section{Algodão}

Antes do processo de deterioração controlada, os valores de teores de água das sementes de algodão variaram de 9,08 a 10,69\%. Após a deterioração controlada das mesmas esse valor foi elevado para $20 \%$. Exceto para o genótipo $\mathrm{MG}$ 3305, os valores de germinação (Tabela 3) das sementes submetidas à deterioração controlada, por 108 horas, foram significativamente $(\mathrm{P}<5 \%)$ inferiores aos observados em sementes não deterioradas.
Para as enzimas esterase, superóxido dismutase, diaforase e malato desidrogenase e proteínas resistentes ao calor não foram encontrados padrões polimórficos entre as cultivares de algodão utilizadas, independente das sementes apresentarem diferença na qualidade fisiológica. Provavelmente, a base genética dessas cultivares é bastante estreita e ou não houve condições de estresse durante o desenvolvimento da semente, impedindo as manifestações de alguns alelos que codificam para as proteínas resistentes ao calor, impedindo a separação das cultivares de algodão por meio desse marcador.

\section{Soja}

Para as sementes das cultivares de soja os valores iniciais de teores de água variaram de 10,90 a 12,54\%. Depois da deterioração das mesmas esse valor foi elevado para $20 \%$. 
Com relação à germinação (Tabela 4), foram observados valores significativamente $(\mathrm{P}<5 \%)$ em sementes submetidas a 96 horas de deterioração quando comparadas às sementes não-deterioradas.

TABELA 3. Valores médios, em porcentagem, de plântulas normais obtidas no teste de germinação de sementes de algodão submetidas e não à deterioração controlada.

\begin{tabular}{ccc}
\hline & \multicolumn{2}{c}{$20 \%$ de Umidade final das sementes após a D.C. } \\
\cline { 2 - 3 } Cultivares & \multicolumn{2}{c}{ Período de deterioração controlada } \\
\cline { 2 - 4 } & \multicolumn{2}{c}{ Germinação (\%) } \\
\hline EPAMIG/Precoce & $66 \mathrm{a}$ & hora horas \\
MG 110 & $69 \mathrm{a}$ & $0 \mathrm{~b}$ \\
MG 304 & $83 \mathrm{a}$ & $2 \mathrm{~b}$ \\
MG 316 & $63 \mathrm{a}$ & $15 \mathrm{~b}$ \\
MG 3305 & $23 \mathrm{a}$ & $17^{\mathrm{a}}$ \\
\hline
\end{tabular}

Médias seguidas pela mesma letra, na coluna, não diferem entre si pelo teste de Tukey, a $5 \%$ de probabilidade.

TABELA 4. Valores médios, em porcentagem, de plântulas normais obtidas no teste de germinação de sementes de soja submetidas e não à deterioração controlada.

\begin{tabular}{|c|c|c|c|c|c|}
\hline \multirow{4}{*}{ Cultivares } & \multicolumn{5}{|c|}{ 20\% de Umidade final das sementes após a D.C. } \\
\hline & \multirow{2}{*}{\multicolumn{2}{|c|}{$\frac{\text { Período de deterioração controlada }(20 \% \mathrm{U})}{\text { Germinação }(\%)}$}} & \multicolumn{3}{|c|}{ Período de deterioração } \\
\hline & & & \multirow[t]{2}{*}{ Cultivares } & \multicolumn{2}{|c|}{ Germinação (\%) } \\
\hline & 0 horas & 96 horas & & 0 horas & 96 horas \\
\hline Conquista & $77 \mathrm{a}$ & $0 \mathrm{~b}$ & \multirow{2}{*}{ BRS 133} & \multirow{2}{*}{$87 \mathrm{a}$} & \multirow{2}{*}{$43 b$} \\
\hline Monarca & $74 a$ & $2 b$ & & & \\
\hline Liderança & $91 \mathrm{a}$ & $29 b$ & \multirow{2}{*}{$\begin{array}{l}\text { BRS } 154 \\
\text { BRS } 216\end{array}$} & $46 \mathrm{a}$ & $0 \mathrm{~b}$ \\
\hline Confianca & $95 \mathrm{a}$ & 270 & & $95 \mathrm{a}$ & \multirow{2}{*}{$\begin{array}{l}15 \mathrm{~b} \\
0 \mathrm{~b}\end{array}$} \\
\hline & & 10 & CD 201 & $78 \mathrm{a}$ & \\
\hline Splendor & $94 a$ & 590 & CD 208 & $91 \mathrm{a}$ & $11 b$ \\
\hline UFV-16 & $97 \mathrm{a}$ & $64 b$ & IAC15-2 & $93 \mathrm{a}$ & $19 b$ \\
\hline Garantia & $61 \mathrm{a}$ & $22 b$ & \multirow{3}{*}{$\begin{array}{l}\text { M-Soy } 6101 \\
\text { M-Soy } 8001\end{array}$} & $82 \mathrm{a}$ & $4 b$ \\
\hline FT-2000 & $95 \mathrm{a}$ & $15 b$ & & $81 \mathrm{a}$ & $0 \mathrm{~b}$ \\
\hline IAC-21 & $86 \mathrm{a}$ & $12 b$ & & \multirow{2}{*}{$94 a$} & \multirow{2}{*}{$0 \mathrm{~b}$} \\
\hline Vencedora & $95 a$ & $38 b$ & M-Soy 8411 & & \\
\hline
\end{tabular}

Médias seguidas pela mesma letra, na coluna, não diferem entre si pelo teste de Tukey, a $5 \%$ de probabilidade.

Em relação aos marcadores enzimáticos, para a enzima esterase (Figura 8A) foram observados quatro padrões eletroforéticos diferentes, permitindo a separação das cultivares em quatro grupos: (1) Monarca, Liderança, Confiança, Splendor, UFV-16, Garantia, FT-2000, BRIAC21, Vencedora, BRS-133 e BRS -216; (2) CD-201, CD-208, IAC 15-2, M-Soy 6101, M-Soy 8001 e M-Soy 8411; (3) Conquista e (4) BRS-154, sendo que para as duas últimas cultivares os padrões eletroforéticos foram específicos. Para a cultivar M-Soy 8411, padrões distintos foram observados em sementes deterioradas e não-deterioradas. Silva (1997) e Vieira (1996) observaram alterações dos padrões eletroforéticos dessa enzima ao avaliarem a associação de microrganismos em sementes e períodos de envelhecimentos. Para a enzima superóxido dismutase (Figura 8B), foram observados dois padrões eletroforéticos diferentes, tendo sido verificado um padrão eletroforético específico na cultivar Conquista. Já Vieira (2004), observou oito padrões eletroforéticos diferentes. Provavelmente essas diferenças possam ser atribuídas às diferentes metodologias utilizadas no processo de extração. De acordo com Alfenas et al. (1998), certas enzimas podem ser controladas por diferentes locos nos vários estádios de desenvolvimento e tecidos, o que deve ser levado em consideração ao se utilizar 
enzimas como marcadores. Devido a falta de estabilidade das cultivares provenientes de sementes deterioradas e não- deterioradas, as mesmas foram separadas em dendrogramas diferentes (Figuras 9 e 10).

FIGURA 8. Zimogramas das isoenzimas esterase (A) e superóxido dismutase (B), extraídas de epicótilos de soja das cultivares Conquista (1), Monarca (2), Liderança (3), Confiança (4), Splendor (5), UFV-16 (6), Garantia (7), FT-2000 (8), BRIAC-21 (9), Vencedora (10), BRS133 (11), BRS 154 (12), BRS 216 (13), CD 201 (14), CD 208 (15), IAC 15-2 (16), M-Soy 6101 (17), M-Soy 8001 (18), M-Soy 8411 (19), submetidas (D) ou não à deterioração controlada

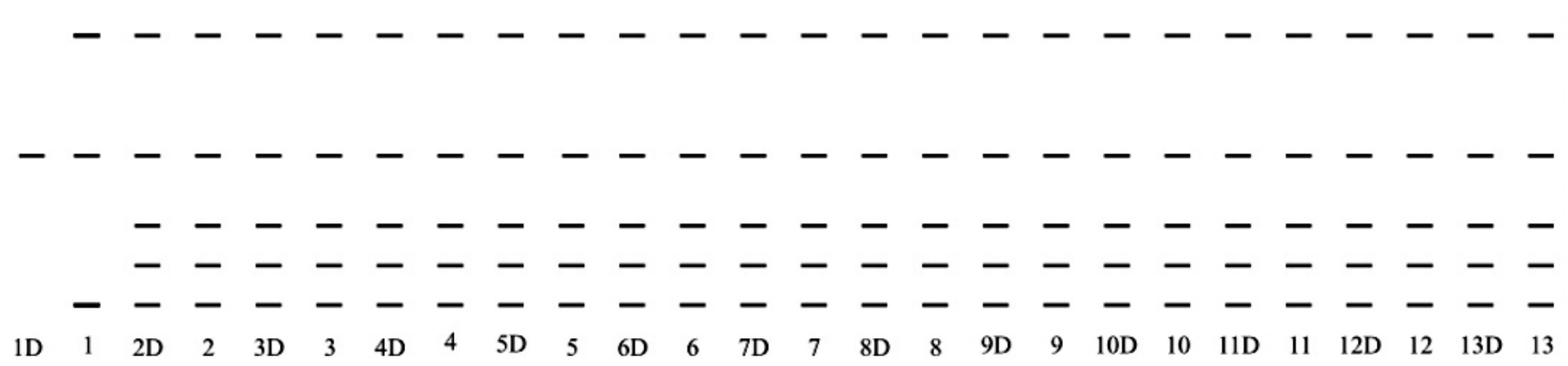

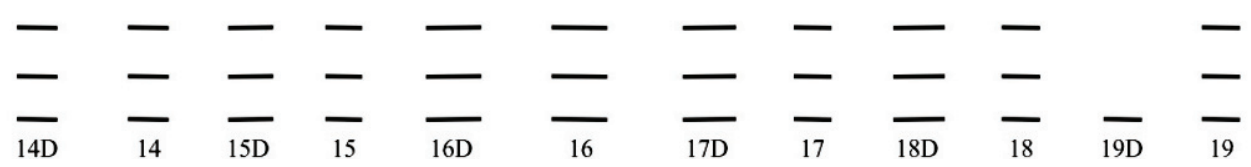

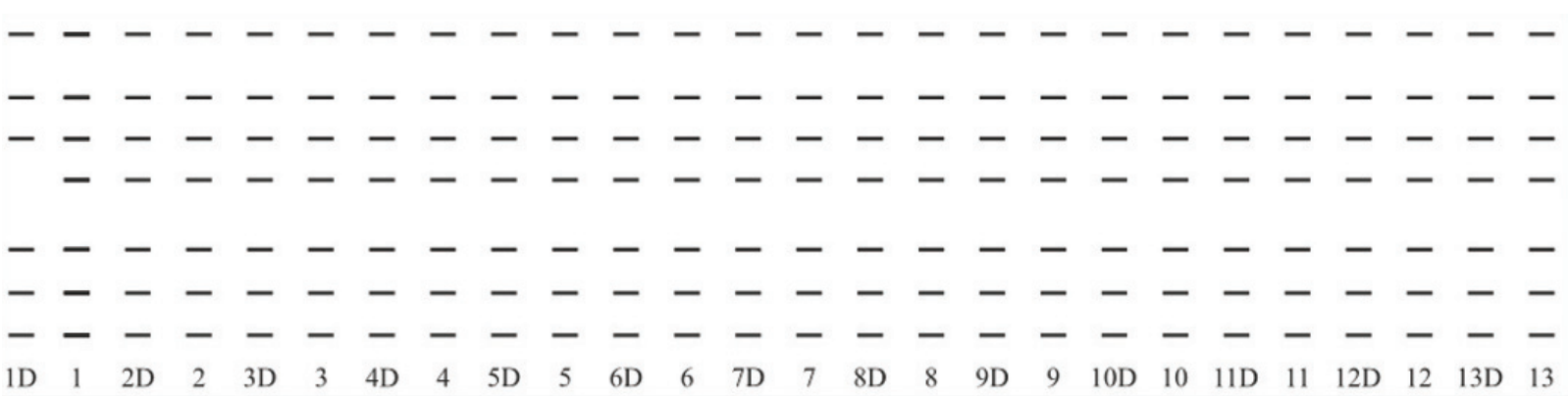

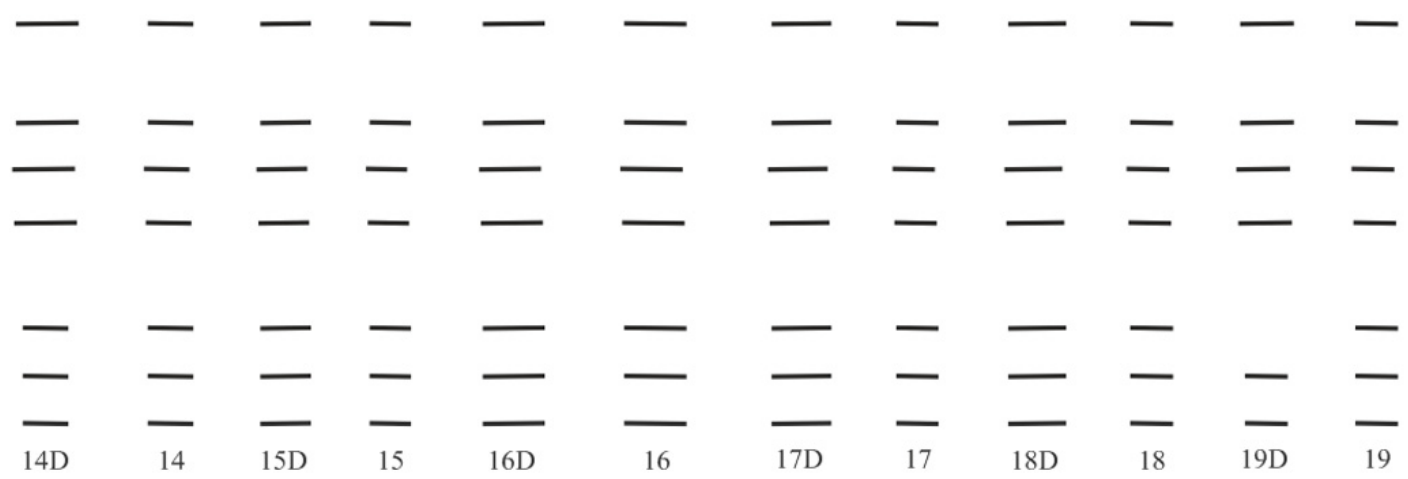


FIGURA 9. Dendrograma de cultivares de soja, utilizando marcadores isoenzimáticos em sementes deterioradas.

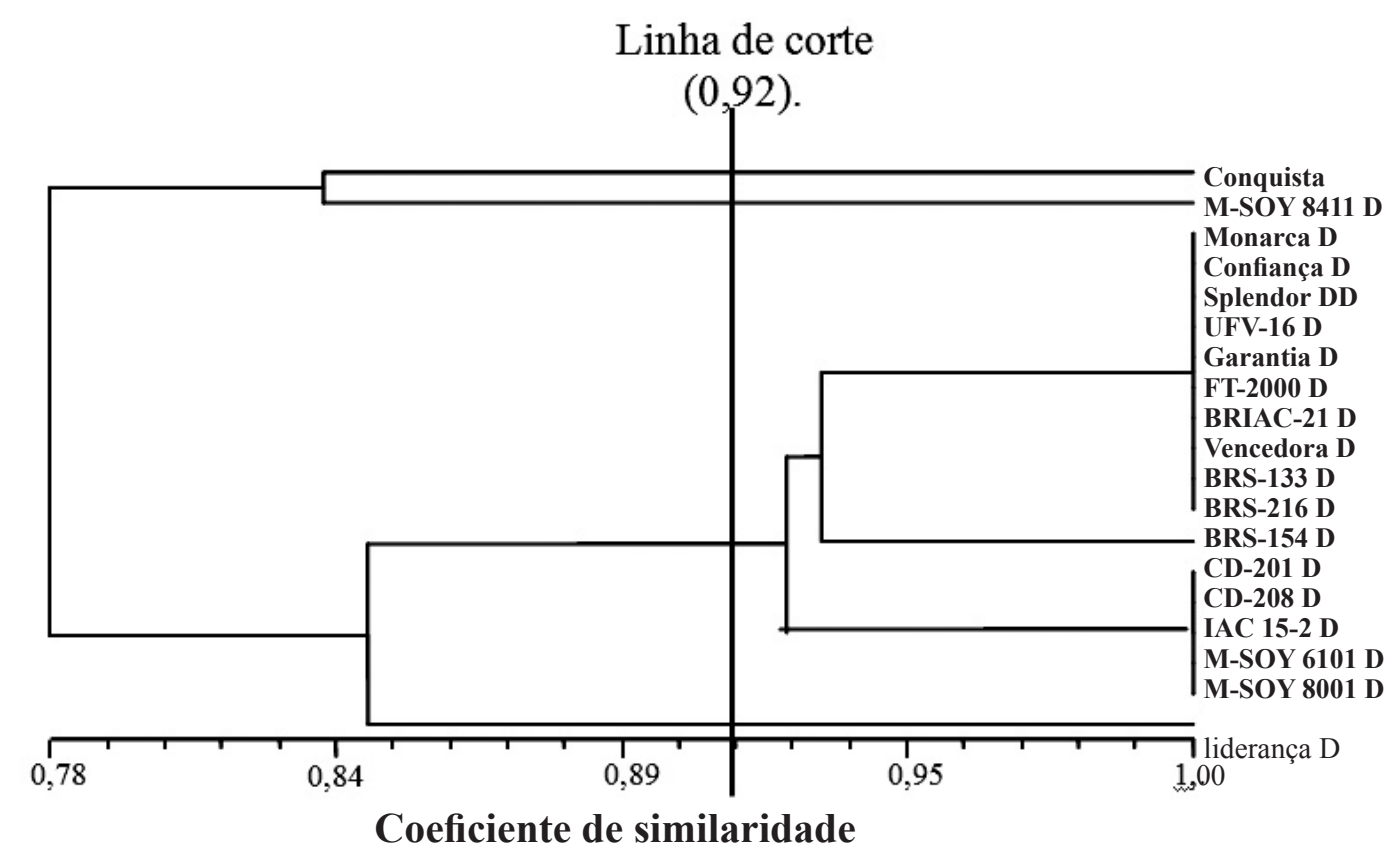

FIGURA 10. Dendrograma de cultivares de soja, utilizando marcadores isoenzimáticos em sementes não deterioradas.

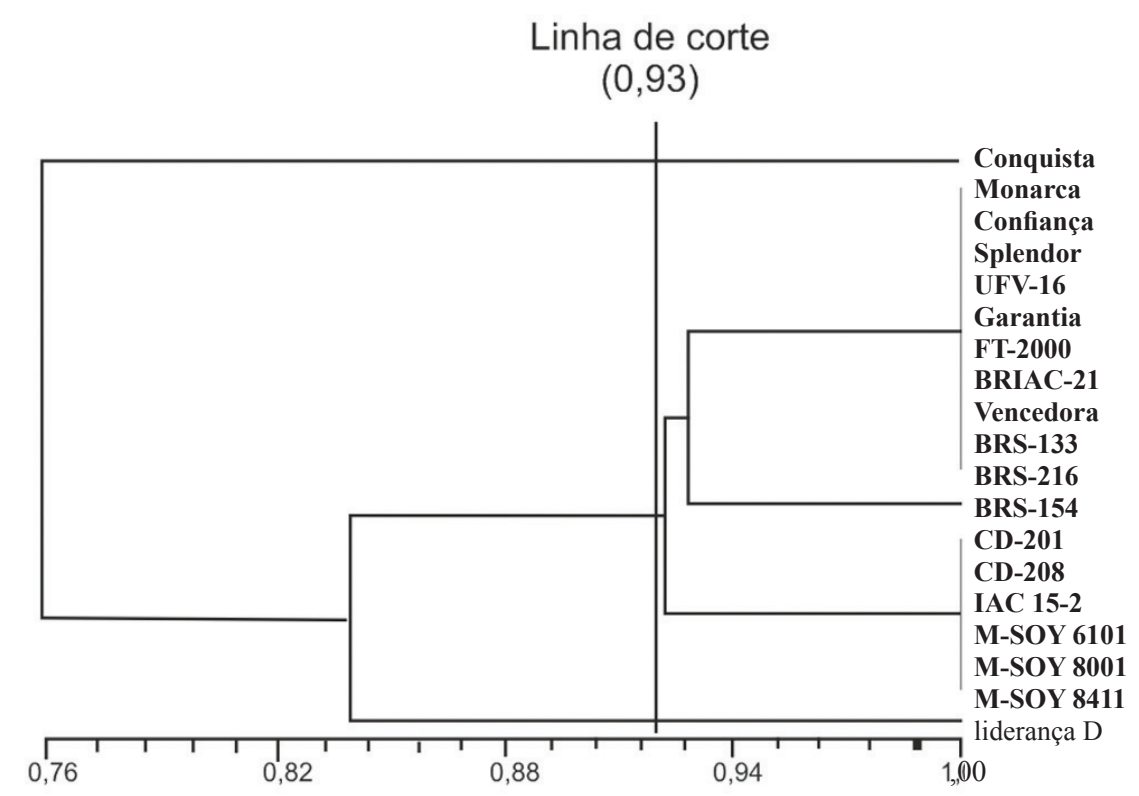

Coeficiente de similaridade 
Para os padrões de proteínas resistentes ao calor das cultivares de soja estudada, não foram observadas bandas polimórficas independente do nível de deterioração das sementes. Vieira (2004) observou uma banda polimórfica na faixa correspondente ao peso molecular de $30 \mathrm{kDa}$, a qual estava presente somente nas cultivares Conquista, Confiança, Splendor, FT 2000 e Monarca. Essa diferença de resultados pode ser devido ao fato de que a expressão de alguns alelos que se codificam para essas proteínas acontece sob condições de estresse durante o desenvolvimento das sementes, o que pode causar o tipo de variação observada nessa pesquisa.

\section{CONCLUSÕES}

De uma maneira geral, dentre os sistemas enzimáticos avaliados em cultivares de milho visando à identificação de cultivares e à certificação da pureza genética de lotes de sementes foram observados polimorfismo e estabilidade para os sistemas álcool desidrogenase, catalase, esterase e superóxido dismutase tanto em sementes de linhagens como nas híbridas com diferentes qualidades fisiológicas.

Para as cultivares de feijão estudado, foram observados padrões polimórficos apenas para o sistema peroxidase e mesmo assim esse se mostrou instável em sementes deterioradas.

Em algodão para as cultivares analisadas foram observados padrões monomórficos para as enzimas esterase, superóxido dismutase, diaforase e malato desidrogenase, que se apresentaram estáveis quanto à qualidade fisiológica das sementes.

Para as cultivares de soja foram observados padrões polimórficos apenas para as enzimas superóxido dismutase e esterase, sendo que essa última se mostrou instável em sementes deterioradas.

Padrões de proteínas resistentes ao calor apresentaram-se polimórficos e estáveis em sementes de milho com diferentes níveis de qualidade. Já para as cultivares de feijão, algodão e soja foram observados padrões monomórficos.

\section{REFERÊNCIAS}

AGUERO, C. O. P. Padrões eletroforéticos de cultivares de soja (Glycine Max (L.) Merril). 2002. 36 f. Dissertação (Mestrado em Ciência e Tecnologia de Sementes) - Faculdade de Agronomia Eliseu Maciel, Pelotas.

ALFENAS, A.C. Eletroforese de isoenzimas e proteínas afins: fundamentos e aplicações em plantas e microrganismos.
Viçosa: UFV, 1998. 574 p.

ALFENAS, A.C. PETERS, I.; BRUNE, W.; PASSADOR, G.C. Eletroforese de proteínas e isoenzimas de fungos e essências florestais. Viçosa: UFV, 1991. 242 p.

BONOW, S. Caracterização morfológica, isoenzimática e molecular de cultivares de arroz. 2004. 125 f. Tese (Doutorado em Fitotecnia) - Universidade Federal de Lavras, Lavras.

BRANDÃO JUNIOR, D.E. Eletroforese de proteínas e isoenzimas na avaliação da qualidade de sementes de milho. 1996. 110 f. Dissertação (Mestrado em Fitotecnia) Universidade Federal de Lavras, Lavras, 1996.

BRASIL. Ministério da Agricultura e Reforma Agrária. Regras para análise de sementes. Brasília, DF: SNDA/ DNDV/CLAV, 1992. 365 p.

HAGIWARA, W.E.; SANTOS, J.B.; CARMO, S.L.M. Use of RAPS to aid selection in common bean backcross breeding programs. Crop Breeding and Applied Biotechnology, Londrina, v.1, n.4, p. 355-362, 2001.

IMOLESI, A.S. Efeito da adubação nitrogenada na qualidade fisiológica, em características morfoagronômicas e nos padrões eletroforéticos de proteínas e isoenzimas de sementes de milho. 1999. 57 f. Dissertação (Mestrado em Fitotecnia) - Universidade Federal de Lavras, Lavras.

ROHLF, F.J. Numerical taxonomy and multivariate analysis system: version 2.11. New York: [s.n.], 1992. 470 p.

ROVERI JOSÉ, S.C.B.; VON PINHO, E.V.R.; SALGADO, K.C.; VON PINHO, R.G. Identificação de cultivares de milho por meio de proteínas resistentes ao calor. Revista Brasileira de Milho e Sorgo, Sete lagoas, v.3, n.1, p.1-9, 2004.

SALGADO, K.C.de C. Certificação da pureza genética em sementes híbridas de milho por meio de marcadores morfológicos e moleculares. 2001. 67 f. Dissertação (Mestrado em Fitotecnia). Universidade Federal de Lavras, Lavras.

SILVA, E.A.A. Padrões eletroforéticos de isoenzimas e proteínas de sementes e coleóptilos de milho em associação com microrganismos. 1997. 87 f. Dissertação (Mestrado em Fitotecnia) - Universidade Federal de Lavras, Lavras.

VIEIRA, E.S.N. Marcadores morfológicos, bioquímicos e moleculares na caracterização de cultivares de soja e café. 2004. 137 f. Tese (Doutorado em Fitotecnia) - Universidade Federal de Lavras, Lavras. 
VIEIRA, E.S.N. Similaridade genética entre cultivares de feijão do grupo carioca por meio de marcadores morfológicos e moleculares visando a certificação da pureza genética. 2000. 84 f. Dissertação (Mestrado em Fitotecnia) - Universidade Federal de Lavras.
VIEIRA, M.G.G. Utilização de marcadores moleculares no monitoramento da qualidade sanitária e nível de deterioração de sementes de algodoeiro (Gossypium hirsustum L.).1996. 114 f. Tese (Doutorado em Fitotecnia) - Universidade Federal de Lavras, 1996. 